\title{
RUPTURE PROCESS OF SUBDUCTION-ZONE EARTHQUAKES
}

\section{Hiroo Kanamori}

Seismological Laboratory, California Institute of Technology, Pasadena, California 91125

\section{INTRODUCTION}

This review is primarily concerned with the rupture process of large subduction-zone earthquakes determined by various seismological methods, and with its interpretation in terms of an asperity model. It is not possible to make a thorough and extensive review on the subject because of the limited length. Consequently, this review is inevitably biased toward the works in which I was directly involved through collaborations with various investigators.

The distribution of large earthquakes along subduction zones has a distinct pattern. Great earthquakes occur in South America, Alaska, the Aleutians, and Kamchatka. In contrast, earthquakes along the Marianas are smaller. The seismicity in other subduction zones is intermediate between these two groups (see Figure 1). Although this regional variation is now generally accepted, it was not until an appropriate method for quantification of large earthquakes was developed that the regional variation was clearly recognized. In view of its fundamental importance in seismology, we first review the quantification method.

\section{QUANTIFICATION OF EARTHQUAKES}

Since the physical process underlying an earthquake is very complex, we cannot express every detail of an earthquake by a single parameter. Nevertheless, it would be useful if we could find a single number that represents the overall physical size of an earthquake. This was the very 


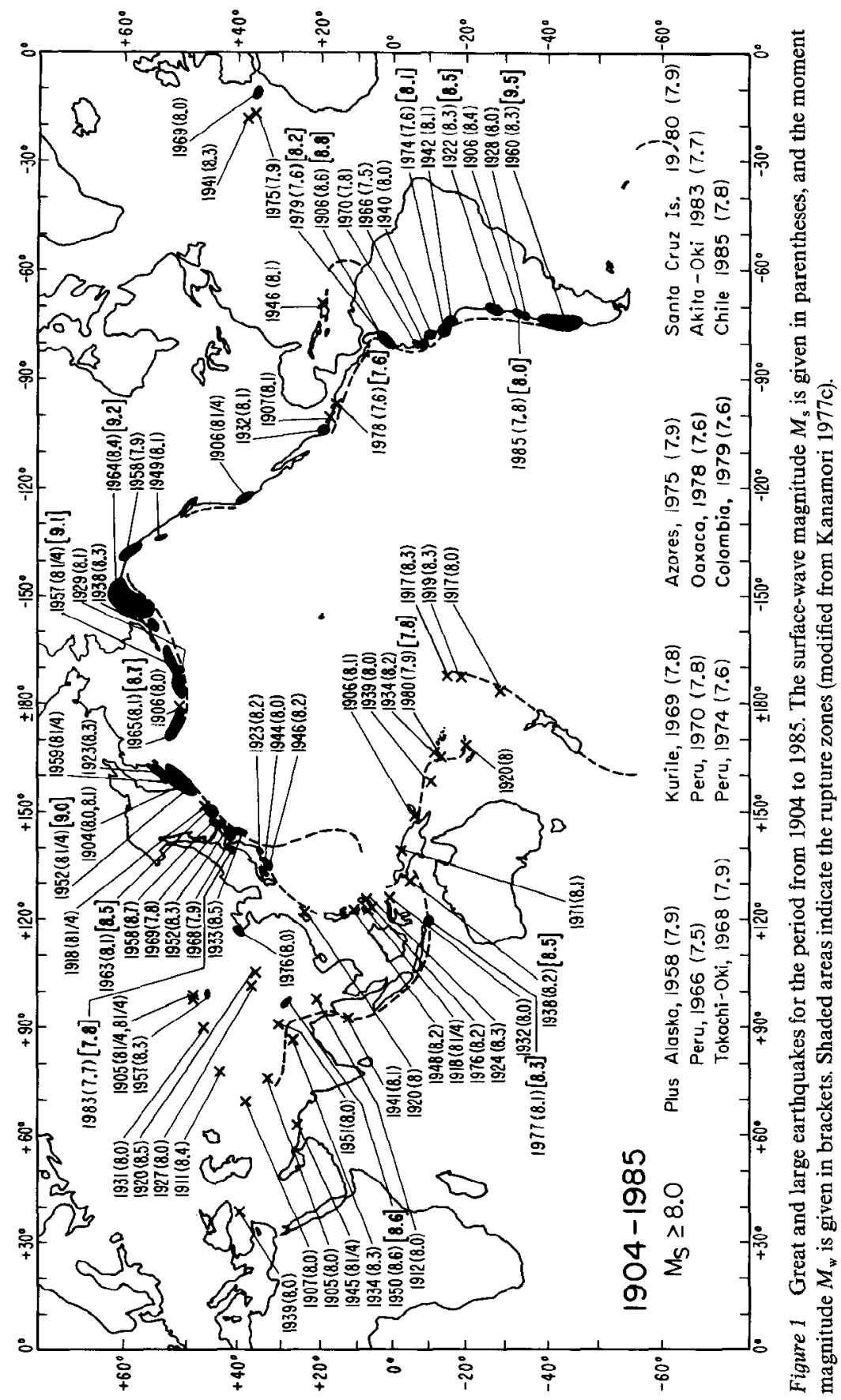


philosophy of Richter's (1935) earthquake magnitude scale. He defined a local magnitude scale $M_{\mathrm{L}}$ for southern California using the amplitude of seismic waves recorded by the Wood-Anderson seismograph. Although $M_{\mathrm{L}}$ is a purely empirical scale without any direct relation to the physical parameters of the earthquake source, it has proved to be extremely useful in studying seismicity.

Gutenberg and Richter (e.g. Gutenberg 1945, Gutenberg \& Richter 1956) extended the magnitude scale to earthquakes worldwide and developed various empirical scales. One of the most widely used scales is the surfacewave magnitude $M_{\mathrm{s}}$, which is defined by the amplitude of surface waves with a period of about $20 \mathrm{~s}$. (For more details on magnitude scales, see Geller \& Kanamori 1977, Bath 1981, Abe 1981, Chung \& Bernreuter 1981, Kanamori 1983.)

An important empirical relation is the magnitude-energy relation obtained by Gutenberg \& Richter (1956):

$$
\log E_{\mathrm{s}}=1.5 M_{\mathrm{s}}+11.8,
$$

where $E_{\mathrm{s}}$ is the energy (in ergs) radiated from an earthquake source in the form of elastic waves. This relation was determined empirically too, and it is subject to large uncertainty. Nevertheless, it is widely used in seismology.

In Figure 1, the surface-wave magnitude $M_{\mathrm{s}}$ is given in parentheses. The 1906 Colombia earthquake has the largest $M_{\mathrm{s}}(8.6)$. However, the size of its rupture zone (indicated by the shaded area in Figure 1) is not the largest. The 1960 Chilean earthquake and the 1964 Alaskan earthquake, for example, have much larger rupture zones, yet the $M_{\mathrm{s}}$ values for these events are smaller. If $M_{\mathrm{s}}$ is related to the energy $E_{\mathrm{s}}$ through (1), and if the energy release per unit rupture area is approximately constant, it is rather strange to have smaller $M_{\mathrm{s}}$ values for events with much larger rupture zones. This problem had been recognized by several investigators, but no systematic investigation was made until long-period seismic waves began to be used for seismic source studies.

The difficulty in using $M_{\mathrm{s}}$ for quantification of large earthquakes arises from the fact that the period of surface waves $(20 \mathrm{~s})$ used for the determination of $M_{s}$ is much shorter than the time scale of faulting associated with great earthquakes, for which the fault length can be as long as $1000 \mathrm{~km}$. The duration of faulting is approximately equal to the fault length $L$ divided by the rupture velocity $V$ (which is usually about $2-3 \mathrm{~km} \mathrm{~s}^{-1}$ ). The time scales of faulting are therefore about 40,100 , and $400 \mathrm{~s}$ for events with rupture lengths of 100,250 , and $1000 \mathrm{~km}$, respectively. Hence, the 20-s surface waves cannot represent the entire rupture process of great earthquakes, and the result is that the $M_{\mathrm{s}}$ scale is saturated (as seen in Figure 1). 
We can circumvent this difficulty by using longer-period surface waves for quantification purposes. Aki (1966a,b) used long-period Love waves to determine the seismic moment $M_{0}$ of the 1964 Niigata earthquake. The seismic moment $M_{0}$ is equal to $\mu D S$, where $D$ is the average slip on the fault, $S$ is the fault area, and $\mu$ is the rigidity of the material surrounding the fault (see Steketee 1958, Maruyama 1963, Burridge \& Knopoff 1964). The amplitude of long-period (longer than the duration of faulting) seismic waves generated by an earthquake is proportional to the seismic moment.

Although the seismic moment represents the size of an earthquake only at very long periods, it has proved to be a useful parameter for overall quantification of earthquakes, particularly for great earthquakes. It can be also related to $E_{s}$ with some assumptions. Kanamori (1977a) shows that

$$
E_{\mathrm{s}}=M_{\mathrm{o}} /(2 \mu / \Delta \sigma) \text {, }
$$

where $\Delta \sigma$ is the average stress drop in earthquakes. Various observations indicate that $2 \mu / \Delta \sigma$ is roughly $2 \times 10^{4}$. With these assumptions, we can estimate $E_{\mathrm{s}}$ from $M_{0}$. Since $M_{0}$ can be reliably determined from observational data, and since the energy is a fundamental physical quantity, this method is useful for quantification purposes. Once $E_{s}$ is determined, it is possible to convert it to a magnitude scale by using (1) inversely, i.e.

$$
M_{\mathrm{w}}=\left(\log E_{\mathrm{s}}-11.8\right) / 1.5
$$

or

$$
M_{\mathrm{w}}=\left(\log M_{0}-16.1\right) / 1.5 \text {. }
$$

$M_{\mathrm{w}}$ is a magnitude scale defined in terms of energy or moment through (3) or (4). It is important to note that unlike other magnitude scales, this scale is not empirical as long as the estimate of the energy through (2) is correct. Since this magnitude is derived from either energy or seismic moment, it is often called either the energy magnitude or the moment magnitude (see also Purcaru \& Berckhemer 1978, Hanks \& Kanamori 1979). For earthquakes smaller than $8, M_{\mathrm{w}}$ generally agrees with $M_{\mathrm{s}}$, which suggests that both of the assumptions used in estimating $E_{\mathrm{s}}$ from $M_{0}$ through (2) and relation (1) are reasonable. Since $M_{0}$ does not saturate as the size of the rupture zone increases, $M_{\mathrm{w}}$ does not saturate. In this regard, $M_{\mathrm{w}}$ is a better parameter for quantification of earthquakes than $M_{\mathrm{s}}$. In Figure 1, $M_{\mathrm{w}}$ values for very large earthquakes are given in brackets. The 1960 Chilean earthquake has the largest $M_{\mathrm{w}}(9.5)$, and the 1964 Alaskan earthquake has the second largest $M_{\mathrm{w}}(9.2)$.

Since $M_{\mathrm{w}}$ is determined from very-long-period waves, it does not necessarily represent the size of an earthquake at short periods (e.g. 1-10 s). However, many studies suggest that earthquake source spectra have certain 
common features, so that the source parameters determined at long periods, such as the seismic moment, can generally represent the entire spectrum reasonably well (Aki 1967, Kanamori \& Anderson 1975, Geller 1976).

The problem of quantification of earthquakes is not very simple. Many parameters are required for a complete description of an earthquake source. However, if we are to use a single parameter to represent the gross size of earthquakes, $M_{\mathrm{w}}$ seems to be the most useful one.

\section{CHARACTERISTICS OF SUBDUCTION ZONES AND SEISMICITY}

Figure 1 depicts the variation of seismicity between different subduction zones more clearly with the unsaturated magnitude scale $M_{\mathrm{w}}$ than with $M_{\mathrm{s}}$. Subduction zones in southern Chile, Colombia, Alaska, the Aleutians, and Kamchatka have great earthquakes with $M_{\mathrm{w}}>8.7$. Subduction zones in the Marianas, Mexico, Tonga Kermadec, and the New Hebrides do not have great earthquakes; most of the major earthquakes in these zones are smaller than 8.2. Since Figure 1 shows the data for the period from 1904 to 1985 , this pattern may not be completely representative of subduction-zone seismicity. However, historical data (which are not shown in Figure 1) indicate that the pattern is generally representative of long-term seismicity of subduction zones. A notable exception is Sumatra. A recent study by Newcomb \& McCann (1984) shows that two large earthquakes $\left(M_{\mathrm{w}}=8 \frac{3}{4}\right.$, $8 \frac{1}{4}$ to $8 \frac{1}{2}$ ) occurred in Sumatra in 1833 and 1861 .

Since most large subduction-zone earthquakes represent the slip between the subducting oceanic plate and the overriding upper plate, the difference in the level of seismicity can be interpreted as the difference in the strength of mechanical coupling between the subducting and overriding plates (Kanamori 1971, 1977b, Kelleher et al 1974, Uyeda \& Kanamori 1979). Subduction zones with great earthquakes are strongly coupled, and conversely those without are weakly coupled. Uyeda \& Kanamori (1979) called the strongly coupled subduction zones the "Chilean-type" subduction zones, and the weakly coupled zones the "Mariana-type" subduction zones, since these two subduction zones are most representative of strongly and weakly coupled zones, respectively.

Since interplate interaction is a key element that determines tectonic features at plate boundaries, one would expect significant tectonic differences between the Chilean-type and the Mariana-type subduction zones. Figure 2 schematically shows characteristic features of the Chilean- and Mariana-type subduction zones.

The differences in various features are summarized in the following (for more details, see Uyeda 1982, 1984). 


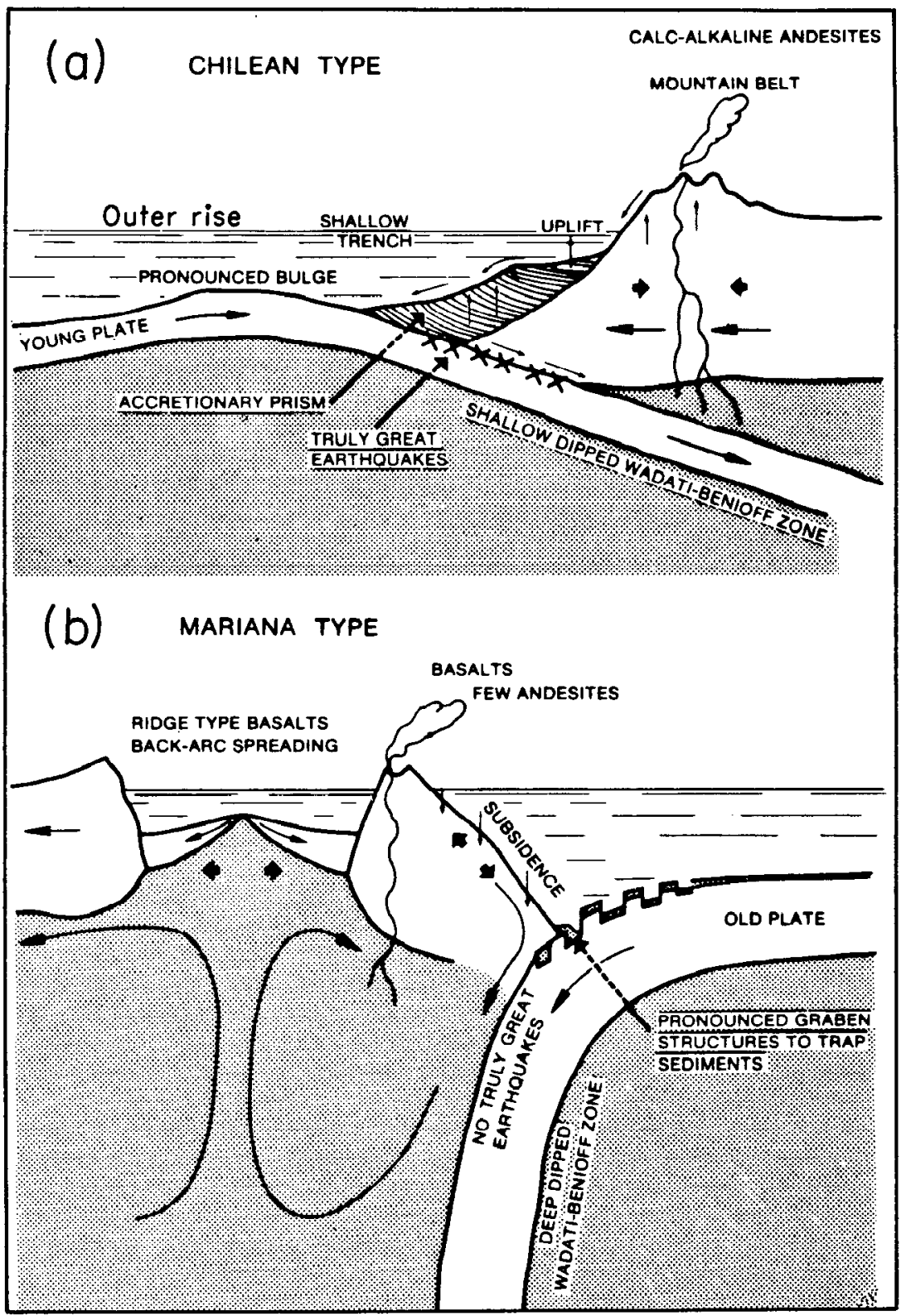

Figure 2 Schematic comparison between the Chilean- and the Mariana-type subduction zones (slightly modified from Uyeda 1984). 
1. BENIOFF-ZONE DIP ANGLES The dip angle of the Benioff (or WadatiBenioff) zone is very shallow in the Chilean-type subduction zone and steep in the Mariana-type subduction zone. Since the width of the interplate contact zone is likely to increase as the dip angle decreases (Kelleher et al 1974), this difference is consistent with the difference in the strength of interplate coupling. The trench is deeper at Mariana-type zones than at Chilean-type zones.

2. EXISTENCE OF THE BACK-ARC BASIN The back-arc basin is commonly found for the Mariana-type subduction zones, but it is rare in the Chileantype zones. A possible reason for this is that the increased horizontal compressional stress associated with the strong plate coupling in the Chilean-type zones inhibits back-arc opening.

3. OUTER RISE Watts \& Talwani (1975) show that the shape of the outer rise (see Figure 2) varies from place to place, reflecting the difference in the magnitude of the compressive stress in the oceanic lithosphere. However, more recent studies indicate that the outer rise is a universal feature of the trench-arc system and that no obvious regional variation exists (Caldwell et al 1976). If the magnitude of the compressive stress increases with the strength of interplate coupling, one would expect a more pronounced outer rise off the Chilean-type subduction zones. The data available now, however, are inconclusive.

In the outer-rise zone, many normal-fault and thrust events occur (Stauder 1968, Chapple \& Forsyth 1979). Normal-fault events are generally shallower than thrust events, and they are considered to result from the bending of the oceanic plate before it subducts beneath the upper plate. Ward (1983) examined the depth of outer-rise events and suggests that the depth of transition from normal to thrust events varies from place to place. In general, it is shallower at the Chilean-type zones than at the Marianatype zones, which suggests that the horizontal compressive stress is larger for the Chilean-type zones.

4. VOLCANIC ROCK TYPES In general, andesites are more abundant in the Chilean-type subduction zones, whereas basalts are more common in the Mariana-type zones (e.g. Miyashiro 1974, Gill 1981). Although the distribution of volcanic rocks is rather complex and there are many exceptions, this general trend can be explained in terms of the different degree of plate coupling. At the Chilean-type zones, the higher compressive stress in the upper plate would increase interaction between the ascending magma and the crust, producing more andesitic volcanic rocks (e.g. Coulon \& Thorpe 1981). However, the detailed mechanism is presently unknown. 


\section{KANAMORI}

5. UPLIFT OF SHORELINES There is a striking difference in the uplift rate of shorelines between Chilean-type and Mariana-type subduction zones. Figure 3 shows the maximum height of the Holocene shoreline $(5000 \pm 1000$ yr old) around the Pacific compiled by Yonekura (1983). The uplift of the shorelines in the Chilean-type zones such as Chile and Alaska is very large, but almost no uplift is observed for the Marianas and Tonga subduction zones (both Mariana-type zones). A notable exception is the New Hebrides. Because of its moderate seismicity, the plate coupling there is not considered to be very strong. However, the uplift is almost as large as in Chile. This can be explained by the collision of buoyant topographic features against the New Hebrides arc (Taylor et al 1980). Such collisions seem to play an important role in controlling the mechanical interaction between the plates.

\section{PLATE MOTION AND SEISMICITY}

Since great subduction-zone earthquakes are ultimately caused by strain accumulation due to plate motion, seismicity is expected to correlate with plate parameters such as the absolute velocity, convergence rate, plate age,

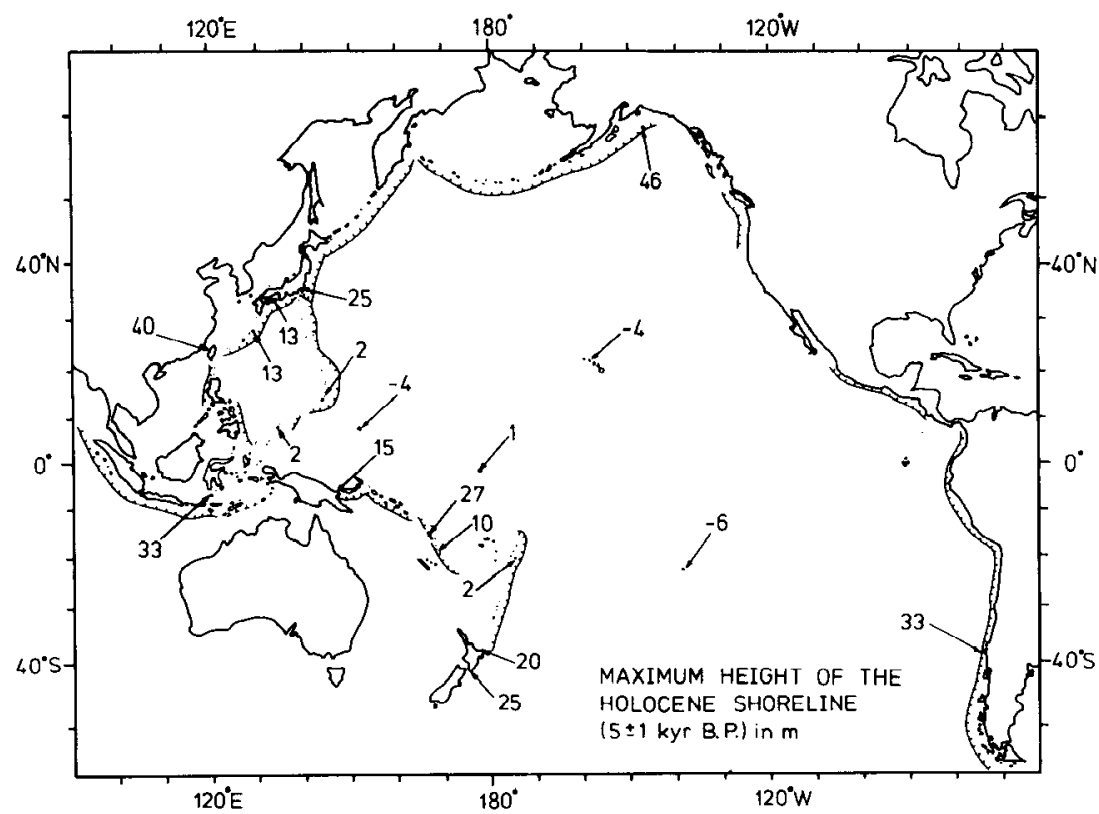

Figure 3 Maximum height of the Holocene shoreline $\left(5 \pm 1 \times 10^{3} \mathrm{yr}\right.$ old $)$ in meters in and around the Pacific (Yonekura 1983). 
Benioff-zone dip angle, and length of the downgoing slab. In order to investigate this problem, it is necessary to quantify the seismicity of each subduction zone. One difficulty is that the instrumental data are available only for roughly the past $80 \mathrm{yr}$.

Ruff \& Kanamori (1980) assumed that the level of seismic activity of an indivudual subduction zone can be represented by the magnitude $M_{\mathrm{w}}$ of the largest earthquake recorded for that subduction zone. Implicit in this assumption is that at least one large earthquake characteristic of each subduction zone occurred during the past $80 \mathrm{yr}$. Ideally, it is best to integrate the seismic energy released during the time period considered and determine the energy release rate per unit time and unit length of the subduction zone. Unfortunately, it is difficult to do this accurately because of the lack of reliable data. In an attempt to do this approximately, Ruff \& Kanamori (1980) considered the overall level of seismicity during the preinstrumental period and modified $M_{\mathrm{w}}$. The modified magnitude $M_{\mathrm{w}}^{\prime}$ differs only slightly from $M_{\mathrm{w}}$, but it represents the overall seismicity of subduction zones better than $M_{\mathrm{w}}$.

Peterson \& Seno (1984) carefully evaluated the magnitude and the seismic moment values listed in various seismicity catalogs and estimated the moment release rate $(M R R)$ per unit time and unit length along the arc. Although considerable error is involved in converting the magnitude to the seismic moment, their estimates of the moment release rate are the best presently available.

Figure 4 compares $M R R$ (determined by Peterson \& Seno 1984) with $M_{\mathrm{w}}^{\prime}$ (determined by Ruff \& Kanamori 1980) for various subduction zones. Since the division of subduction zones is slightly different between the two studies, some adjustments are made in this comparison, as explained in the figure caption. In general, $\log (M R R)$ correlates very well with $M_{\mathrm{w}}^{\prime}$; this correlation suggests that $M_{\mathrm{w}}^{\prime}$ is a good parameter to represent the level of seismicity in each subduction zone. The regression line shown in Figure 4 gives $M R R=10^{\left(1.2 M_{\mathrm{w}}^{\prime}+18.2\right)} \mathrm{dyne}-\mathrm{cm} /(100 \mathrm{~km}-100 \mathrm{yr})$. In this sense, it is more appropriate to interpret $M_{\mathrm{w}}^{\prime}$ as a parameter that represents the rate of seismic moment release rather than as the magnitude of the characteristic earthquake in the region.

Ruff \& Kanamori (1980) correlated $M_{\mathrm{w}}$ (or $M_{\mathrm{w}}^{\prime}$ ) with various plate parameters. For example, Figure $5 a$ shows the relation between $M_{\mathrm{w}}^{\prime}$ and the plate convergence rate $V$. In general, as the convergence rate increases, one would expect stronger interplate interaction and, therefore, higher seismicity. Although Figure $5 a$ shows a generally positive correlation, the scatter is very large, which suggests that other factors are also important in controlling seismicity.

Another important plate parameter is the age of the subducting plate. 
Since the older plates are more dense, they have a stronger tendency to sink spontaneously, thereby decreasing the strength of mechanical coupling (Molnar \& Atwater 1978, Vlaar \& Wortel 1976, Wortel \& Vlaar 1978). Figure $5 b$ shows the relation between $M_{\mathrm{w}}^{\prime}$ and the age $T$ of the subducting plate. The correlation is negative, as expected, but the scatter is very large; this result suggests that the plate age is not the sole controlling factor of seismicity.

Figure 5 indicates that the convergence rate $V$ and the plate age $T$ together might be controlling seismicity. Ruff \& Kanamori (1980) performed a three-parameter regression analysis in the form $M_{\mathrm{w}}^{\prime}=$ $a T+b V+c$, where $a, b$, and $c$ are constants. Using the data listed in Table 1 of Ruff \& Kanamori (1980), they obtained a relation,

$$
M_{\mathrm{w}}^{\prime}=-0.00953 T+0.143 V+8.01
$$

where $T$ is in million years and $V$ is in $\mathrm{cm} \mathrm{yr}^{-1}$.

Figure 6 compares the observed $M_{\mathrm{w}}^{\prime}$ values with those calculated from $T$ and $V$ through (5), showing a good correlation between the observed and

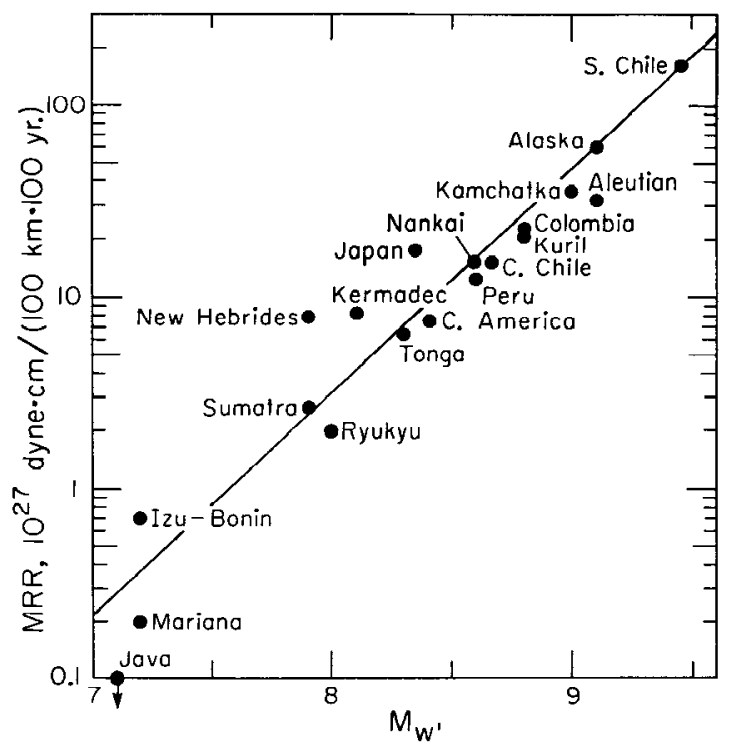

Figure 4 The relation between the seismic moment release rate $M R R$ [in $10^{27}$ dyne-cm $/(100$ $\mathrm{km}-100 \mathrm{yr})]$ and $M_{\mathrm{w}}^{\prime}$. The data are taken from Peterson \& Seno (1984) and Ruff \& Kanamori (1980). Peterson \& Seno's regionalization of the subduction zones is modified as follows (the first and the second names in the parentheses refer to Peterson \& Seno's and Ruff \& Kanamori's data, respectively): (Peru-south, Peru), (average of Central America and Mexico, Central America), (Aleutian-east and Aleutian-west, Aleutian), (Nankai, SW Japan), (Japan, NE Japan). 


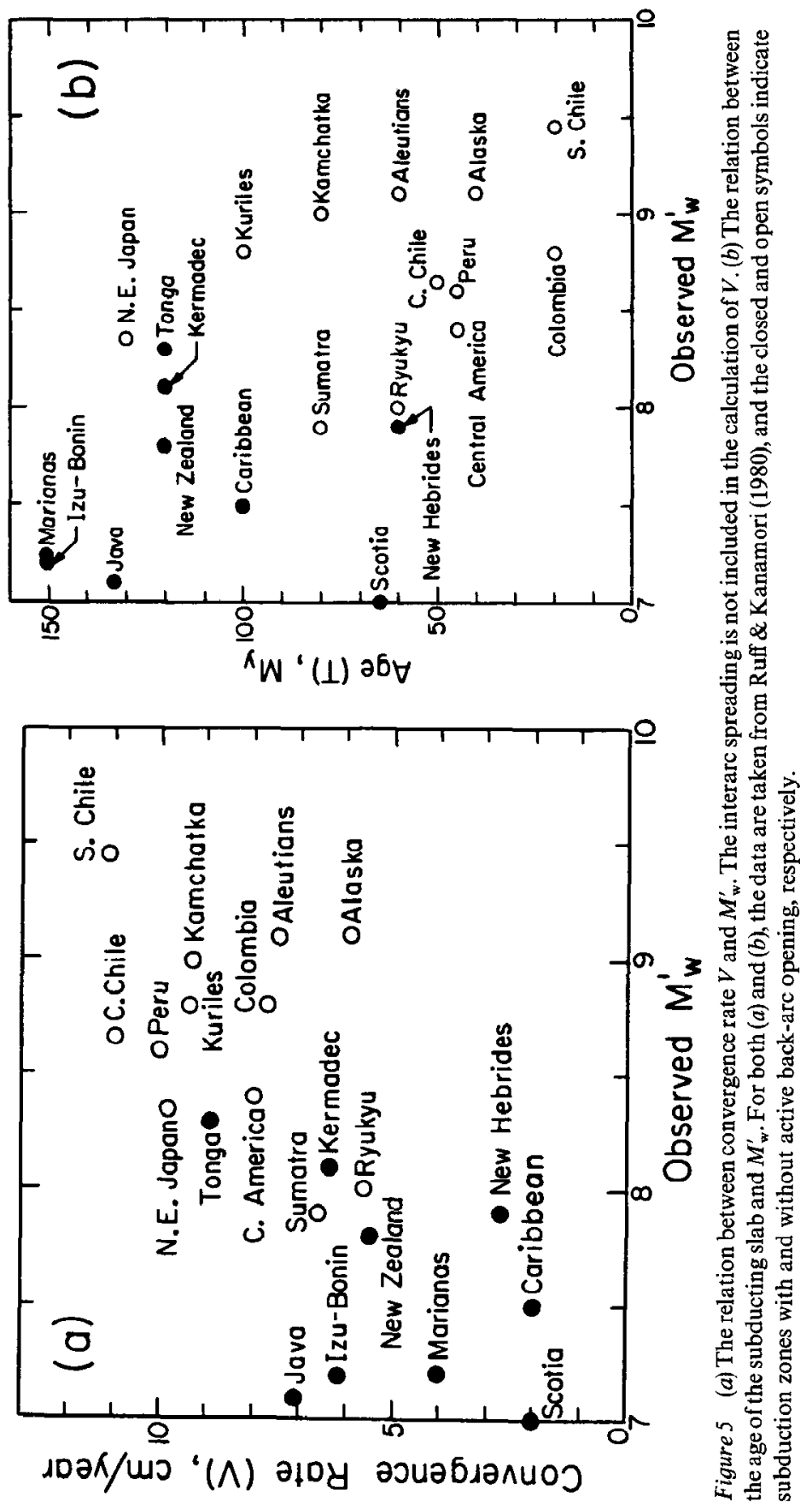




\section{KANAMORI}

calculated $M_{\mathrm{w}}^{\prime}$ values. Also note that the subduction zones with active backarc opening plot in the lower-left corner of Figure 6, which indicates good correlation between low seismicity and back-arc opening. Ruff \& Kanamori (1980) tried similar correlations between $M_{\mathrm{w}}^{\prime}$ and other plate parameters. They found that among all the three-parameter combinations considered, the $M_{\mathrm{w}}^{\prime}-T-V$ combination yields the best correlation.

It should be noted that (5) is obtained empirically without any particular physical model. It is possible that other parameters are equally important. For example, Uyeda \& Kanamori (1979) and Peterson \& Seno (1984) suggest that the absolute velocity of the upper plate is important in determining the strength of plate coupling. In any case, despite the lack of clear physical models, (5) provides a useful scheme for interpreting global seismicity in terms of a simple plate interaction model.

An alternative approach would be to build a specific physical model and test it by using $M_{\mathrm{w}}$ and other plate parameters. Hager et al (1983) used a global convective flow model of the Earth's mantle (Hager \& O'Connell 1981) to determine the flow patterns and pressure distributions in the mantle. They found that the model that allows whole mantle flow yields

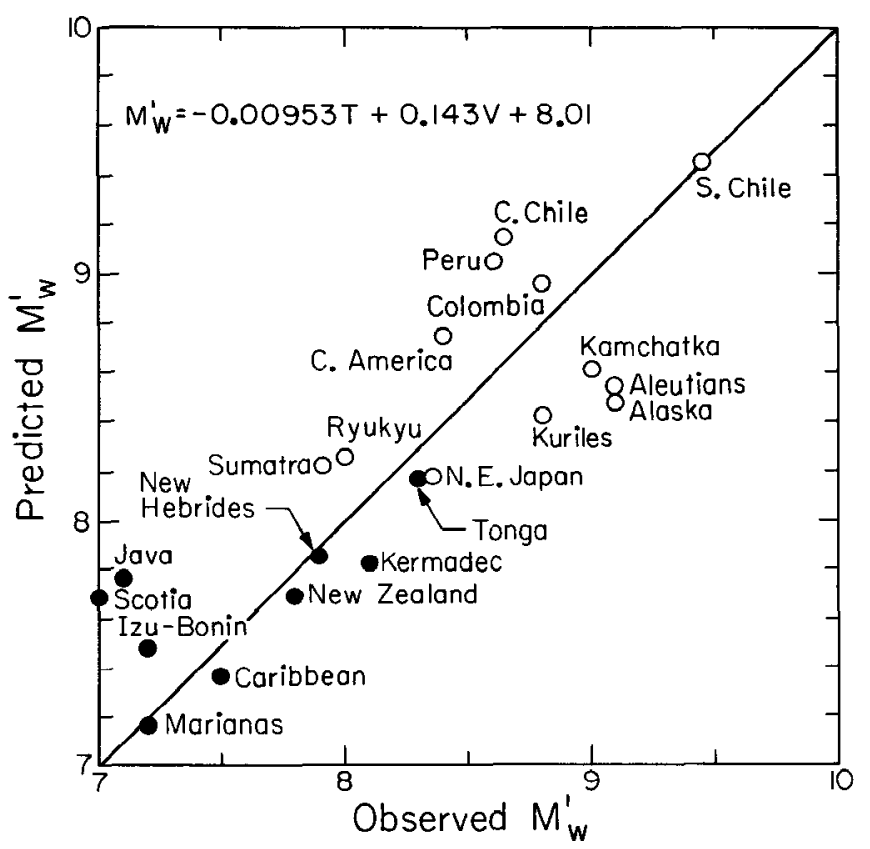

Figure 6 The relation between $M_{\mathrm{w}}^{\prime}$ calculated from $T$ and $V$ using the relation $M_{\mathrm{w}}^{\prime}=$ $-0.00953 T+0.143 V+8.01$ and the observed $M_{\mathrm{w}}^{\prime}$. Closed and open symbols indicate subduction zones with and without active back-arc opening, respectively. 
flow patterns that are consistent with the observed Benioff-zone geometries. Higher pressure gradients between the mantles beneath the trench and the back-arc area computed for this model correlate well with higher $M_{\mathrm{w}}$. Since a larger pressure gradient tends to press the downgoing slab more tightly against the upper plate, this correlation is reasonable. The correlation is especially good when it is taken for the following three parameters: pressure gradient, age of the subducting plates, and $M_{\mathrm{w}}$. This example demonstrates that seismicity data can provide important constraints on the dynamics of the Earth's mantle.

\section{ASPERITY MODEL}

As shown in the preceding sections, the global variation of seismicity can be interpreted in terms of the variation of strength of mechanical coupling. However, so far it is not clear what is causing this regional variation of strength.

The width of the lithospheric interface has been correlated with the maximum length of rupture zones by Isacks et al (1968) and Kelleher et al (1974). In this case, the width of the contact zone is the primary factor determining the coupling strength. Kanamori $(1971,1977 b)$ interpreted the variation of interplate coupling in terms of a weakening of the lithospheric interface. Topographic features on the subducting seafloor, such as seamounts and fracture zones, may be controlling the coupling strength (Kelleher \& McCann 1976, 1977). However, until recently little was known about the stress distribution on the fault plane of great earthquakes.

Lay \& Kanamori (1980) studied body waves and surface waves of large earthquakes in the Solomon Islands region in an attempt to determine the stress distribution on the thrust plane. They found that relatively shortperiod (about $10 \mathrm{~s}$ ) seismic body waves are radiated from only small parts of the entire rupture plane, which generates longer-period (about $200 \mathrm{~s}$ ) surface waves and over which the aftershocks occur (Figure 7a). They interpreted the results in terms of an asperity model, as shown by Figure 7. This asperity model is an outgrowth of laboratory experiments on rock friction. Byerlee (1970) and Scholz \& Engelder (1976) suggested that the two sides of a fault are held together by areas of high strength, which they termed asperities. Extending this model to earthquake faults, we call the areas on the fault plane from where relatively short-period seismic body waves are radiated the (fault) asperities; it is assumed that the stronger spots are responsible for high-frequency seismic radiation. However, the fault asperities can be areas of geometrical irregularity. From seismic observations alone, it is not possible to determine their physical properties. The parts of the fault plane where only long-period seismic radiation occurs 
or where processes with longer time scales than that of seismic radiation (e.g. creep, aftershock expansion, etc) occur are called the weak zones.

Lay \& Kanamori (1980) examined seismograms of events from other subduction zones and found that the complexity of body waveforms is very different. For example, the events that occur in the Kurile Islands generally radiate body waves with very complex waveforms, and these waveforms suggest a rather heterogeneous and complex asperity distribution on the fault plane (see Figure $7 b$ ).

Lay \& Kanamori (1981) and Lay et al (1982) extended these results to a more general picture (see Figure $7 c$ ). In the typical Chilean-type subduction zones, the fault plane is uniformly strong (all asperity), and the size of the rupture zone is determined by major transverse tectonic structures such as fracture zones and ridges (Mogi 1969a, Kelleher \& Savino 1975). In subduction zones such as the Aleutian Islands and the Solomon Islands, asperities are relatively large, but they are surrounded by weak zones. The sizes of earthquakes are not as large as those that occur in Chile and Alaska, but failure of one asperity often triggers failure of adjacent asperities, which results in large multiple events or earthquake multiplets (two or more distinct events closely spaced in time). In subduction zones such as the Kurile Islands, asperities become smaller and more heterogeneous in size. In the Mariana-type subduction zones, the fault plane is uniformly weak (no asperities), and no large earthquakes occur.

Ruff \& Kanamori (1983a) used seismic body waves to directly determine the asperity distributions on the fault plane of several large earthquakes. Figure 8 illustrates this method.
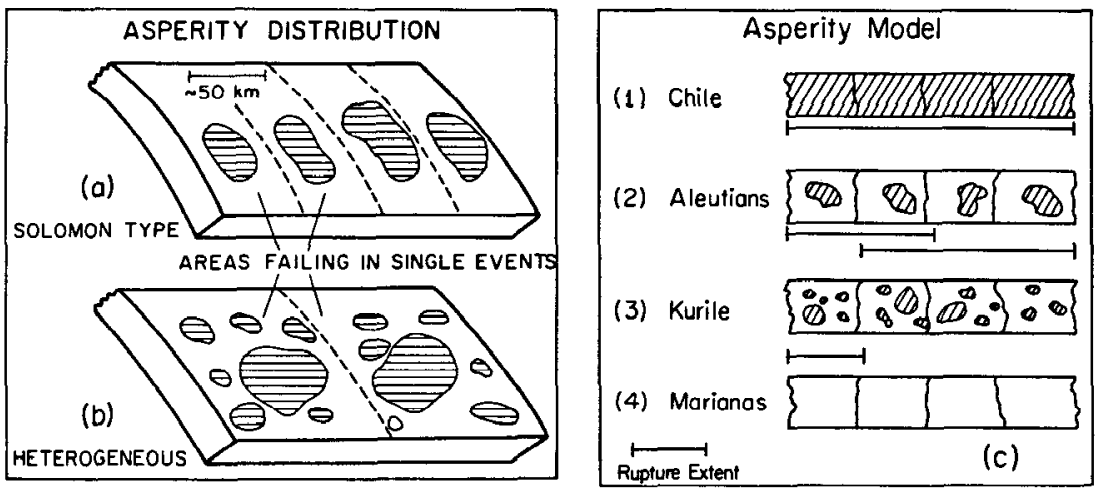

Figure 7 Representation of the interplate interface in subduction zones by an asperity model. Hatched areas indicate asperities. (a) A model for the Solomon Islands region. The asperities are of comparable size. (b) A model for a more heterogeneous interface in regions such as Japan and the Kurile Islands. (c) A schematic representation of asperity distributions for different regions (from Lay \& Kanamori 1980, 1981, Lay et al 1982). 
Figure $8 a$ shows a simple fault with length $L$ and area $S$. At point $A$ in the near field, the displacement would look like a ramp function (Figure $8 b$ ). The total displacement is equal to half the offset $D$ of the fault. The build-up time $\tau$ is approximately (within a factor of two) equal to $L / V$, where $V$ is the rupture velocity. At point $B$ on the other side of the fault, the displacement time function is reversed in polarity (Figure $8 c$ ). At a point in the far field, the displacements from both sides of the fault interfere. As a result, the time function in the far field is given by the time derivative of the near-field displacement (Figure 8d). The area under the bell-shaped function is proportional to the seismic moment, and the width is approximately equal to $\tau$. This function is often called the far-field source time function, and it is used to characterize the source complexity. We can determine the fault dimension and the seismic moment from the duration and the area of the far-field time function.

Figure $8 f$ shows a more complex case that involves two asperities. The near-field and far-field displacements for this case are shown in Figures $8 g$ and $8 h$. The far-field time function has two pulses, each representing one of the asperities. From the far-field time function like the one shown in Figure $8 \mathrm{~h}$, we can determine the asperity distribution. However, because of $(a)$ the distortion of the waveform during propagation between the source and the

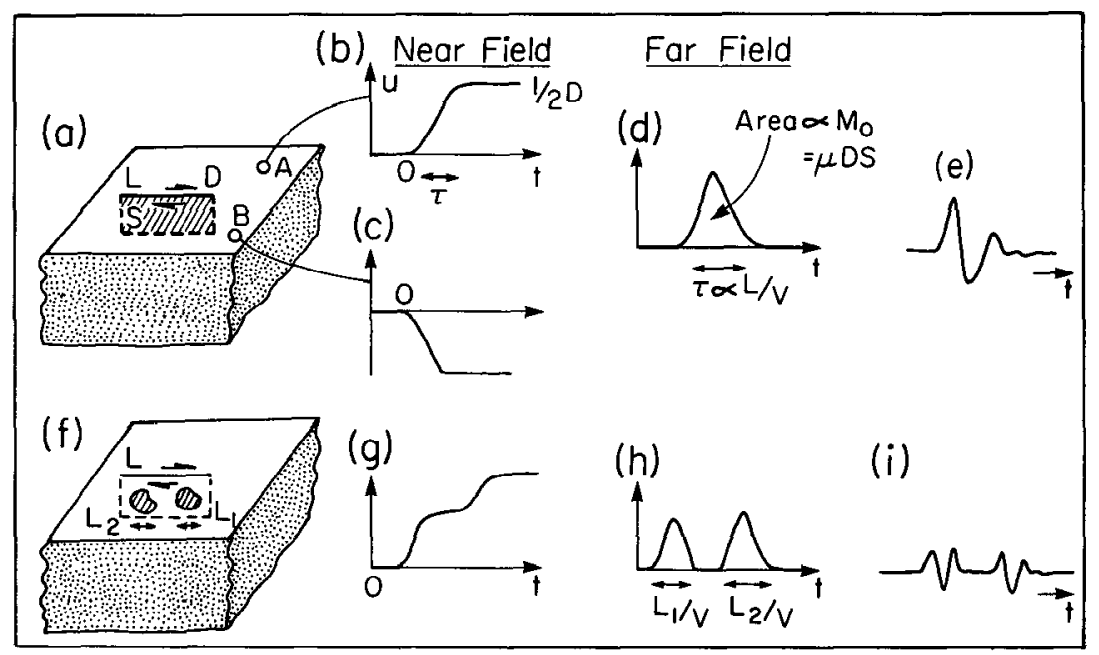

Figure 8 Fault model and far-field body-wave time function. (a) A simple fault model with uniform strength (i.e. single asperity). (b) The near-field displacement at point A. (c) The nearfield displacement at point B. (d) The far-field displacement, often called the far-field source time function. (e) The far-field displacement viewed through a seismograph (seismogram). $(f)$ A complex fault model with two asperities. $(g)$ The near-field displacement. $(h)$ The farfield displacement. (i) Seismogram. 


\section{KANAMORI}

station and $(b)$ the instrument response, the observed waveforms are very complex (Figures $8 e, i$ ), and the determination of the far-field time function is extremely difficult. Furthermore, for very large earthquakes such as the 1964 Alaskan earthquake, relatively few usable seismograms exist because most of the seismograms were off-scale. Ruff \& Kanamori (1983a) used diffracted $P$ waves to circumvent this difficulty.

Figure 9 compares the waveforms of four large earthquakes: the 1964 Niigata earthquake $\left(M_{\mathrm{w}}=7.6\right)$, the 1963 Kurile Islands earthquake $\left(M_{\mathrm{w}}=8.5\right)$, the 1965 Rat Islands earthquake $\left(M_{\mathrm{w}}=8.7\right)$, and the 1964 Alaskan earthquake $\left(M_{\mathrm{w}}=9.2\right)$. The Niigata earthquake is the smallest in this group. Since the fault length of this earthquake is about $60 \mathrm{~km}$, the duration of faulting is about $25 \mathrm{~s}$, and the body waveform viewed through the passband of the long-period WWSSN seismograph (i.e. $5-50 \mathrm{~s}$ ) is a simple impulse (Figure $9 a$ ), which suggests a simple source (Figure 10a), at least as viewed through this passband. In contrast, the waveform of the Kurile Islands earthquake is far more complex and suggests a complex asperity distribution (Figure 10b). The waveforms of the Alaskan earthquake are unique. Not only is the amplitude very large, but also the period is very long. This long-period wave indicates that the asperity responsible for the body-wave radiation is very large. By removing the effects of the wave propagation and the instrument from the body waves, Ruff $\&$ Kanamori (1983a) determined that the length scale of the asperity is about $200 \mathrm{~km}$ (Figure 10d). The pattern of

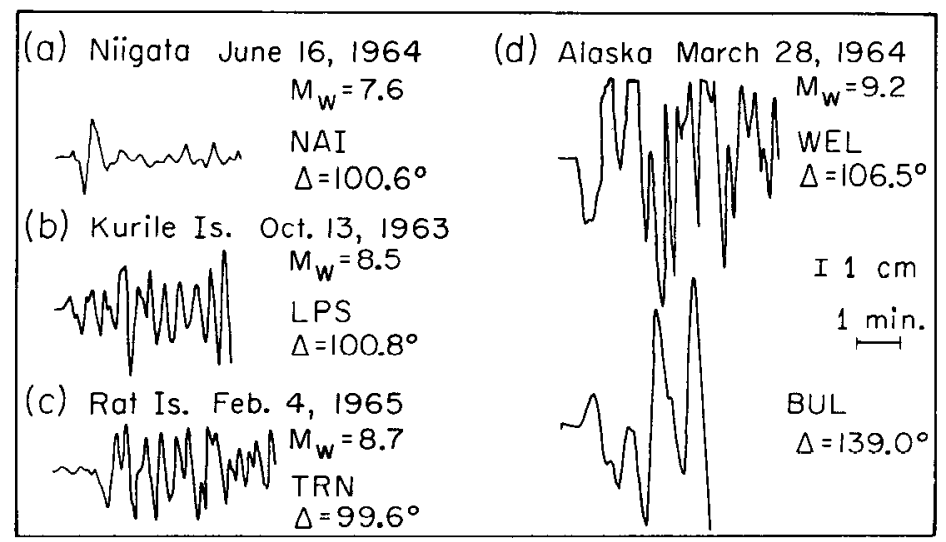

Figure 9 Representative seismograms for four large earthquakes, plotted with the same amplitude and time scales. For the Alaskan earthquake, the seismogram at $\Delta=106.5^{\circ}$ is offscale, and another seismogram from a station in the shadow zone is shown. Note the large amplitude and the long period of the Alaskan earthquake seismograms (modified from Ruff \& Kanamori 1983a). 
asperity distribution for the Rat Islands earthquake is intermediate between the Kurile Islands and the Alaskan earthquakes (Figure 10c).

Hartzell \& Heaton (1985) determined far-field time functions from $P$ waves of 63 large, shallow subduction-zone earthquakes that occurred in the circum-Pacific belt. They used the seismograms recorded at Pasadena by a Benioff long-period seismograph. Since the passband of this instrument is about $2.5-50 \mathrm{~s}$, the complexity of the source can be resolved only on this time scale. Viewed through this passband, the seismograms showed no obvious global trends in the character of far-field time functions. However, most of the subduction zones do behave characteristically, and this finding suggests regional variations of asperity distribution. For example, the time functions for earthquakes from central Chile, Peru, the Solomon Islands, and the New Hebrides are simple and smooth. The Solomon Islands earthquakes, in particular, are characterized by unusually broad, simple time functions (Figure 11). These results are consistent with the expansion patterns of aftershocks, as is shown later.

More recent studies by Beck \& Ruff (1984), Schwartz \& Ruff (1985), and Kikuchi \& Fukao (1985) have succeeded in resolving important details of the source process. Figure 11 compares the results obtained by different investigators (Hartzell \& Heaton 1985). Although the details differ between different studies, the general features as shown in Figure 10 seem to be well established.

If the stress drop $\Delta \sigma_{\mathrm{a}}$ at the asperity does not vary from event to event, the magnitude of the tectonic stress drop $\Delta \sigma$ is approximately equal to $\Delta \sigma_{\mathrm{a}}\left(S_{\mathrm{a}} / S\right)$, where $S$ is the total area of the fault plane and $S_{\mathrm{a}}$ is the total area of the asperities. We conclude that in the context of the asperity model, the regional variation of the strength of mechanical coupling (i.e. $\Delta \sigma$ ) is a manifestation of the regional variation of asperity size and its distribution.

This type of asperity model is a gross generalization of the actual stress distribution on the fault plane, but it also provides simple physical interpretations of some seismicity patterns (e.g. swarms, quiescence, foreshock) before large earthquakes (e.g. Kanamori 1981).

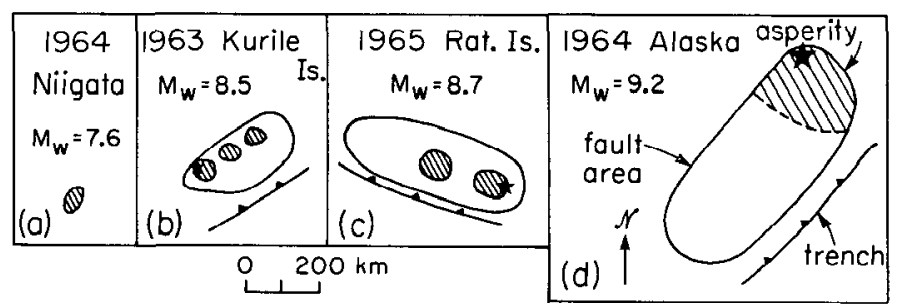

Figure 10 Interpretation of Figure 9 in terms of the asperity model (modified from Ruff \& Kanamori 1983a). Compare Figures 9 and 10 with Figures $8 i$ and $8 f$. 


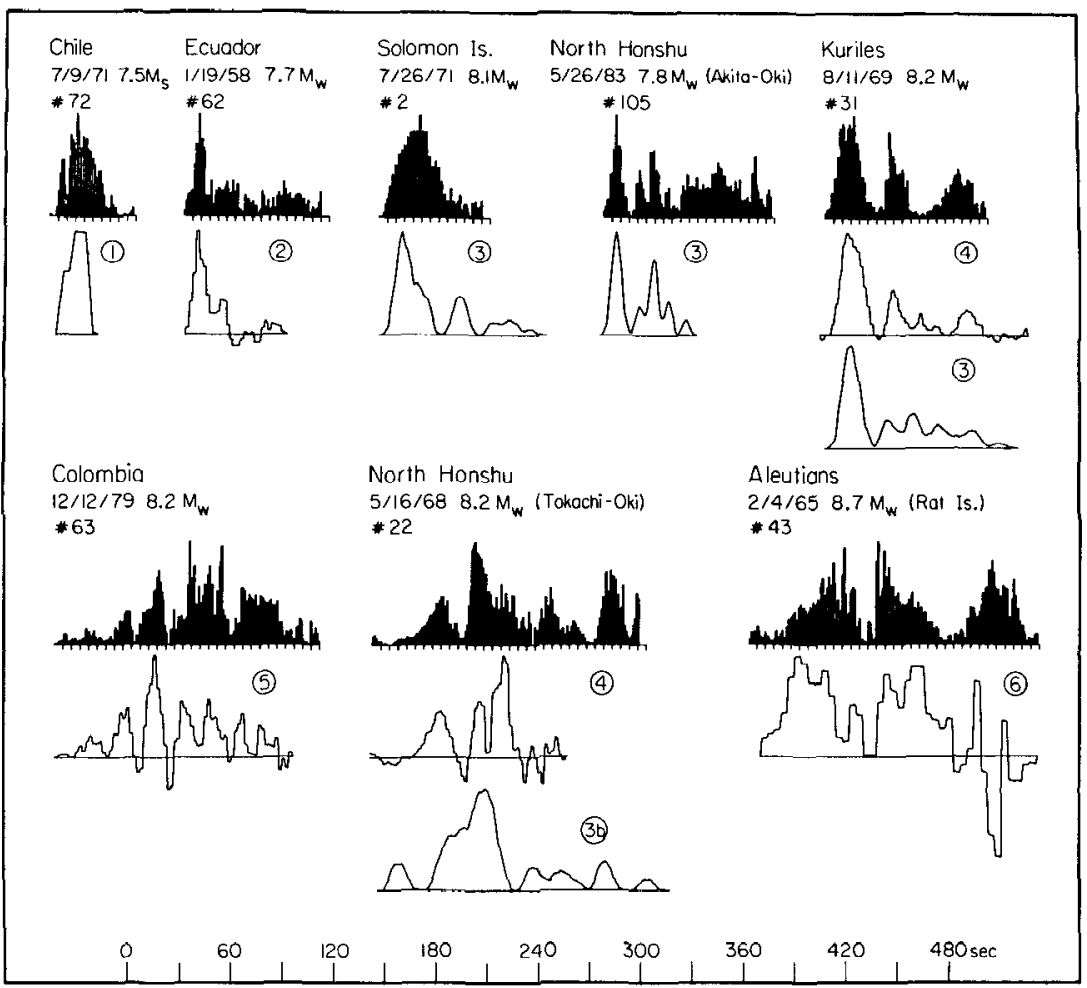

Figure 11 Comparisons of far-field time functions obtained by different investigators. The shaded functions are from Hartzell \& Heaton (1985). Sources are as follows : (1) Malgrange et al (1981); (2) Beck \& Ruff (1984); (3) M. Kikuchi (written communication); (3b) Kikuchi \& Fukao (1985); (4) Schwartz \& Ruff (1985); (5) S. Beck \& L. Ruff (unpublished work); (6) Ruff \& Kanamori (1983a) (after Hartzell \& Heaton 1985).

Another class of heterogeneous fault models is the barrier model proposed by Das \& Aki (1977). In this model, strong spots (barriers) on the fault plane do not fail during the mainshock. The differences between the asperity model and the barrier model are discussed by Madariaga (1979) and Rudnicki \& Kanamori (1981). It is difficult to distinguish between these two models from seismic data alone.

\section{EXPANSION PATTERN OF AFTERSHOCK AREA}

Further evidence for regional variations in mechanical heterogeneities of fault zones, here characterized by asperity distributions, came from expansion patterns of aftershock areas. Although the mechanism of 
aftershock occurrence is not fully understood, the spatial distribution of aftershocks and its expansion pattern seem to provide clues to the mechanical property of the source region. Mogi $(1968,1969 \mathrm{~b})$ noted significant variations of expansion patterns of aftershock areas and interpreted them in terms of regional variations of tectonic structures.

Tajima \& Kanamori (1985a) developed a method to objectively define the aftershock area by using spatio-temporal patterns of seismic energy release; they then used this method to examine the aftershock area expansion patterns of about 50 earthquakes. Four examples are shown in Figure 12. For the 1964 Alaskan earthquake, no significant expansion occurred, while the aftershock area of the 1978 Miyagi-Oki, Japan, earthquake expanded nearly threefold in area during the period from 1 day to 100 days after the mainshock. Tajima \& Kanamori (1985b) defined the 100 -day linear expansion ratio $\eta_{1}(100)$ by the ratio of the maximum linear dimension of the aftershock area observed at 100 days after the mainshock to that of the 1-day aftershock area. Figure 13, which shows $\eta_{1}(100)$ plotted at the respective mainshock epicenter, demonstrates a distinct regional

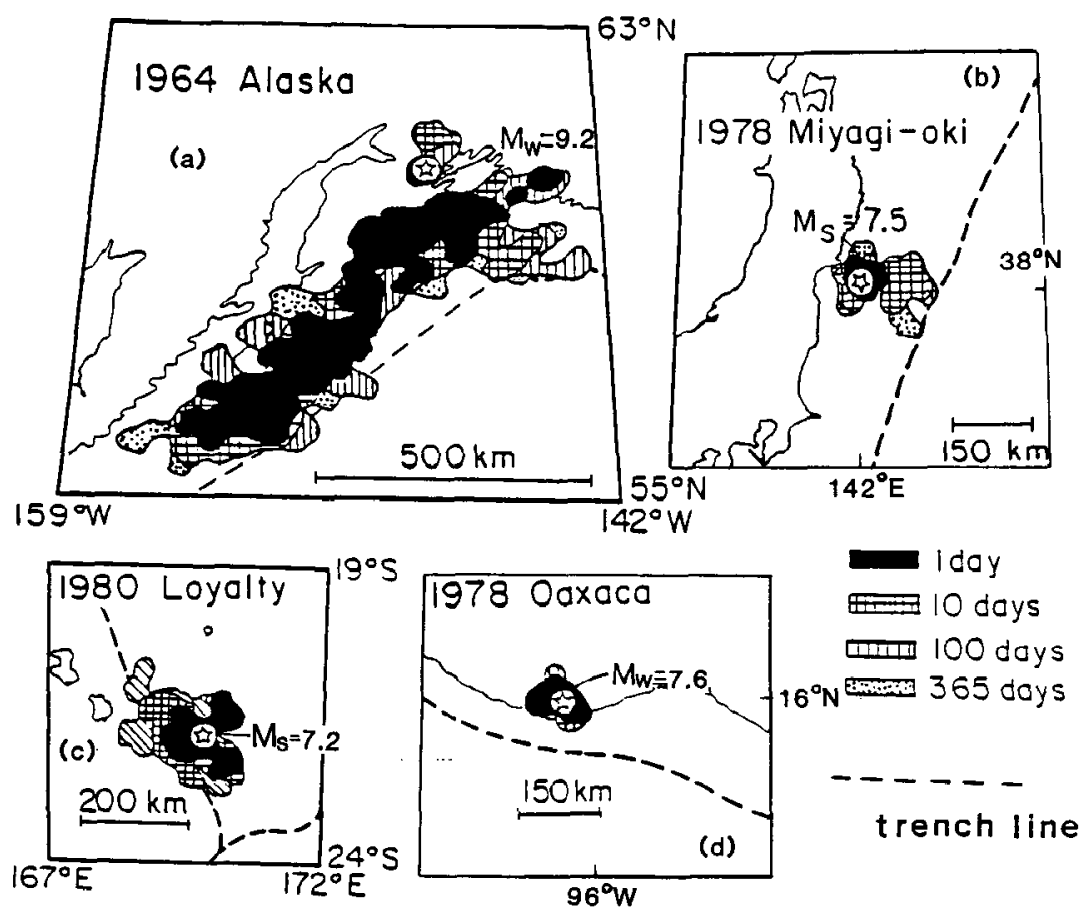

Figure 12 The aftershock areas determined at four different times : 1 day, 10 days, 100 days, and 1 yr (slightly modified from Tajima \& Kanamori 1985b). 


\section{KANAMORI}

variation. In the western Pacific subduction zones (northeastern Japan, Ryukyu, the Philippines, New Hebrides, and Tonga), the expansion ratios are generally large. On the other hand, in the northern Pacific subduction zones and along the Central American trench, the ratios are generally small. The events in the Solomon Islands (Nos. 18 and 27) are doublets and are indicated by an open circle (large expansion); however, this large linear expansion could be due to the occurrence of the second event of the doublet. If each event of the doublet is considered separately, they would have been classified as events with a small expansion ratio. In the South American subduction zones, the expansion ratios vary from event to event.

These results can be explained in terms of the asperity model, as shown by Figure 14. The rupture during the mainshock mostly involves asperities. After the main rupture is completed, the stress change caused by the mainshock gradually propagates outward into the surrounding weak zones. This stress propagation manifests itself as an expansion of aftershock activity. If the fault zone consists of large asperities abutting each other (e.g. Chilean-type), little expansion occurs (Figure 14b). If the average size of asperities is relatively small, then the strength of interplate coupling is moderate. If these asperities are densely distributed and separated by small weak zones, no extensive aftershock expansion is expected (Figure 14c). The Mexican subduction zone is a typical example of this type. In contrast, if smaller asperities are sparsely distributed (Mariana-type), large expansion

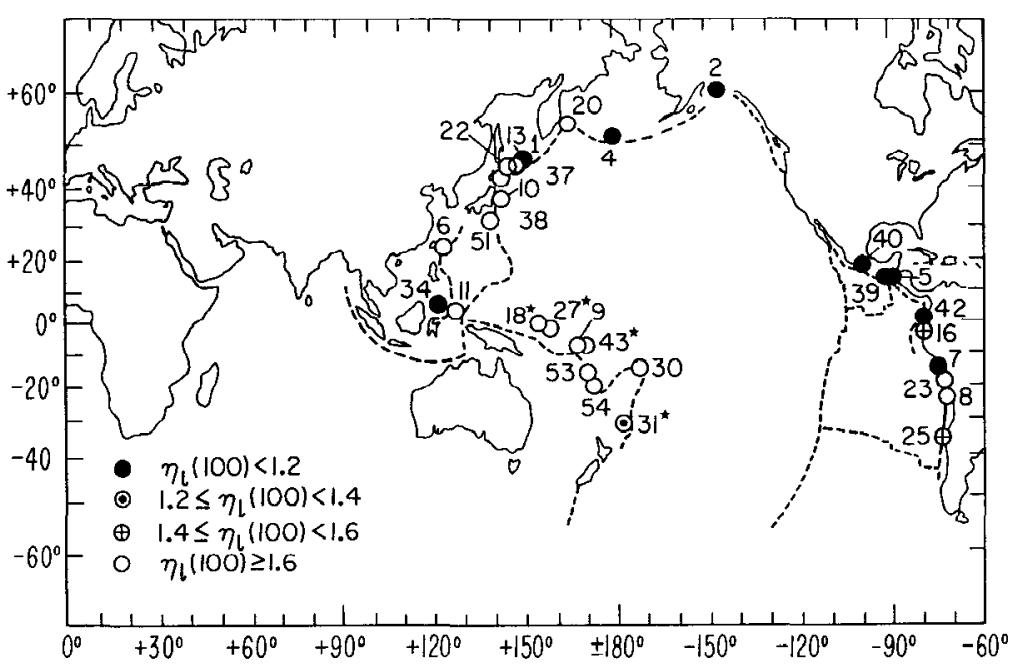

Figure 13 Plot of the 100-day linear expansion ratio $\eta_{1}(100)$. The number beside each symbol corresponds to the event number listed in Tajima \& Kanamori (1985b). The asterisk indicates the first event of a doublet (after Tajima \& Kanamori 1985b). 


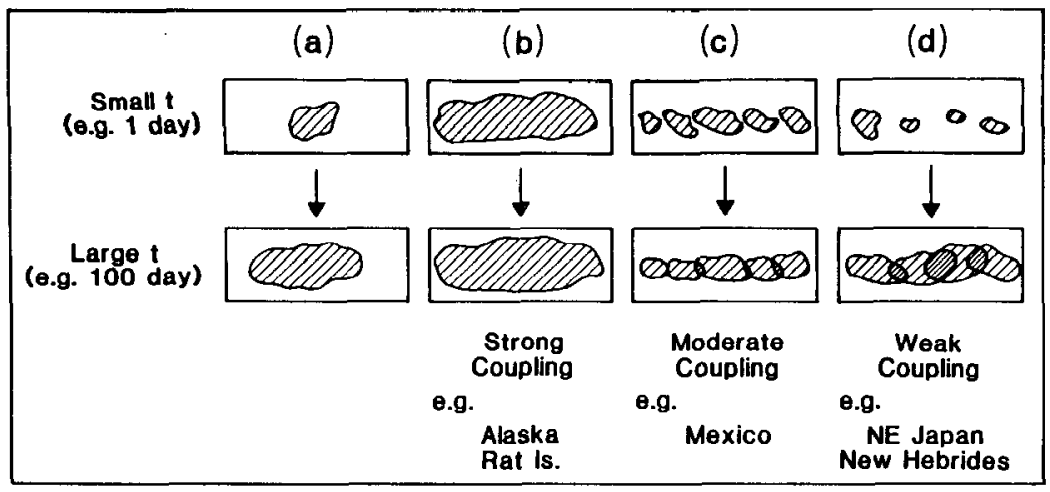

Figure 14 Schematic figure showing typical expansion patterns of aftershock area. The hatched areas indicate aftershock areas. The aftershock areas at small $t$ (time) are considered asperities on a fault zone. (a) A typical expansion pattern. The aftershock area expands from the asperity to the surrounding weak zone. (b) A fault zone with a uniform, large asperity. The aftershock area does not expand, and interplate coupling is strong. (c) Densely distributed small asperities. The aftershock zone expands little, and interplate coupling is moderate. (d) Sparsely distributed small asperities. An aftershock area expands significantly, often overlapping with that of the adjacent event. Interplate coupling is weak (after Tajima \& Kanamori 1985b).

ratios are to be expected, and the aftershock areas of adjacent events may overlap each other (e.g. northeastern Japan, the Philippines, New Hebrides, and Tonga-Kermadec; Figure 14d).

The pattern shown in Figure 13 is generally consistent with that of asperity distribution inferred from the locations of great earthquakes and from the body-wave studies, and it renders support to the asperity model.

\section{THE ASPERITY}

In the preceding discussion, we introduced asperities as spots of increased strength on the fault plane without specifying what they physically are. As shown earlier, the age of the subducting plate and the plate convergence rate seem to have a strong influence on plate coupling. On the other hand, the coupling strength is also controlled by the heterogeneity on the fault plane. However, the relation between plate parameters such as the age, the convergence rate, and the fault-plane heterogeneities is not obvious. Ruff \& Kanamori (1983b) discussed this subject in detail and suggested various possibilities, but at present there is no definite answer to this question.

One important factor, however, seems to be the trench sediment. The amount of trench sediments is very different between different subduction zones because it is controlled by factors such as the supply rate from the 
adjacent land and the disposal rate. In some subduction zones, sediments riding on the oceanic plate are scraped off and deposited to form accretionary prisms, while other subduction zones seem to be subducting most of the sediments without forming accretionary prisms (see, e.g., Scholl et al 1977, Hilde 1983, Uyeda 1984). Hilde \& Sharman (1978) suggest that horst-and-graben structures, which are often seen on the seafloor near the trench, may be acting as a carrier of the sediments beneath the upper plate, as illustrated in Figure 15. The horst-and-graben structure is thought to be a result of plate bending before subduction. Ruff(1985) proposed that thick excess sediments at subduction zones form a uniform interplate contact plane enhancing the coupling, whereas seafloors with horst-and-graben structures develop a heterogeneous contact plane that decreases the strength of mechanical coupling. Figure 16 shows the global distribution of subduction zones with excess trench sediments (ETS) and with horst-andgraben structures (HGS). Also shown in this figure are the epicenters of large earthquakes. In general, the subduction zones that have experienced very large earthquakes are associated with ETS, and those without large earthquakes are characterized by HGS. We note several exceptions. The Sumatran subduction zone is characterized by ETS, but no great earthquakes have occurred there in this century. Newcomb \& McCann (1984), however, documented two great Sumatran earthquakes that occurred in 1833 and 1861. The subduction zone off southwestern Japan has not experienced events with $M_{w} \geqslant 8.2$ during this century, but it is the site of two $M_{\mathrm{w}}=8.1$ earthquakes in this century and many historical great earthquakes. The subduction zone off the Washington-Oregon coast of North America (Juan de Fuca subduction zone) has not experienced great earthquakes for at least the past $150 \mathrm{yr}$; however, its long-term seismic potential is unknown and is presently a matter of debate (see Heaton \& Kanamori 1984).

Another interesting aspect of this model is that it may provide a link between the $M_{\mathrm{w}}^{\prime}-T-V$ relation and the asperity distribution. There is a general correlation between the dip angle and the age of the oceanic plate

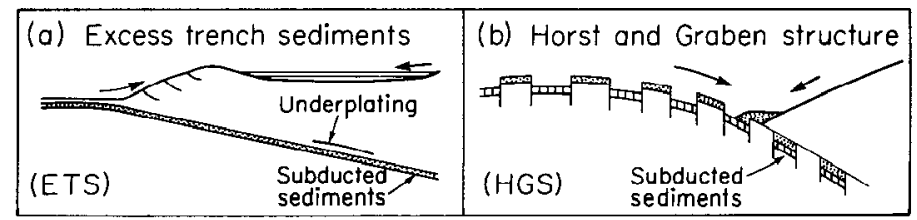

Figure 15 Two trench morphologies. (a) Excess trench sediments. Sediments are scraped off on subduction and form an accretionary prism. (b) Horst-and-graben structure. A welldeveloped horst-and-graben structure provides a mechanism to carry down the sediments (after Ruff 1985). 


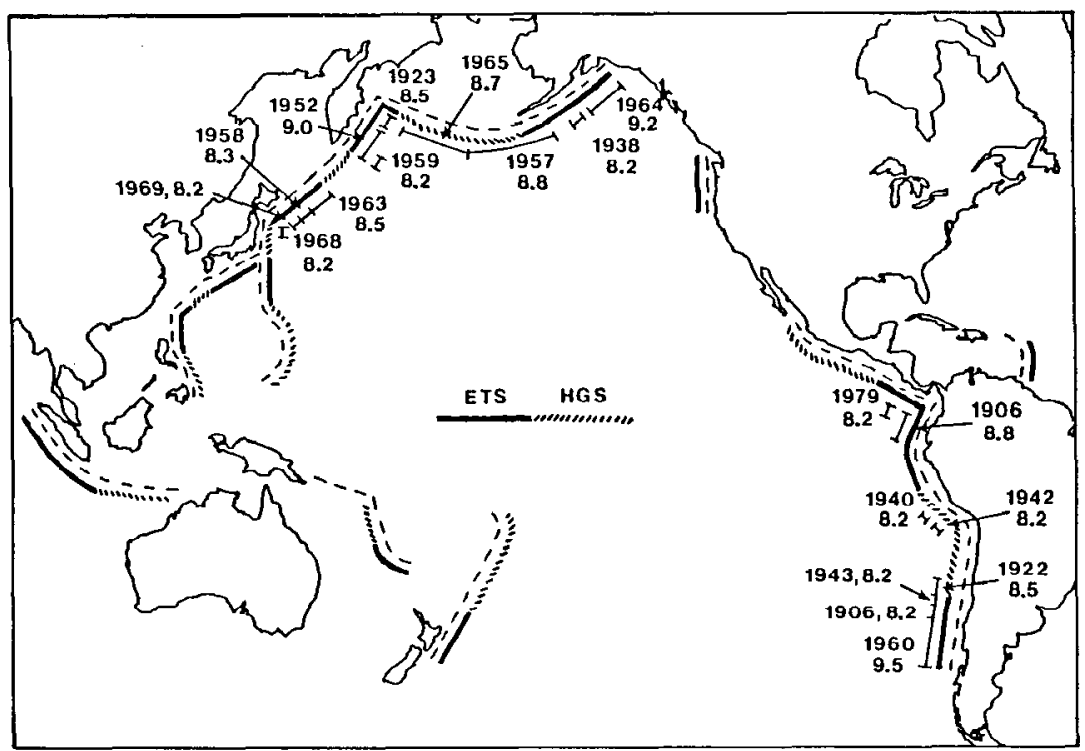

Figure 16 Classification of subduction zones by the two trench morphologies (ETS and HGS). Also shown are $M_{\mathrm{w}}$ values and the approximate rupture zones of major earthquakes (after Ruff 1985).

(Molnar \& Atwater 1978). Therefore, older plates may develop more pronounced horst-and-graben structures, since they are bent more sharply before subduction, which results in smaller asperities and weaker coupling.

\section{RELATED PROBLEMS}

\section{Evaluation of Seismic Potential}

The $M_{\mathrm{w}}^{\prime}-T-V$ relation given by (5) could be used to evaluate the seismic potential of subduction zones that have not experienced great earthquakes in historical times. Since the age $T$ of the subducting plate and the convergence rate $V$ are known for most subduction zones, $M_{\mathrm{w}}^{\prime}$ can be estimated from (5).

Heaton \& Kanamori (1984) applied (5) to the subduction zone off the Oregon-Washington coast (Juan de Fuca subduction zone), where no great earthquake is known to have occurred for at least the past $150 \mathrm{yr}$. Furthermore, instrumentally determined seismicity during the last $80 \mathrm{yr}$ is extremely low. Hence, if we extrapolate the past seismicity to the future, we would expect a very low seismic potential. However, the estimated $T$ and $V$ are about $8 \mathrm{Myr}$ and $3.5 \mathrm{~cm} \mathrm{yr}^{-1}$, respectively, which would yield a $M_{\mathrm{w}}^{\prime}$ of 8.4 through (5); this $M_{\mathrm{w}}^{\prime}$ value suggests a high seismic potential. Since (5) is 


\section{KANAMORI}

obtained entirely empirically, this value of $M_{\mathrm{w}}^{\prime}$ should not be taken at face value. However, it does mean that the Juan de Fuca subduction zone is similar, with respect to the plate-boundary characteristics, to other subduction zones that have experienced great earthquakes, and further investigations into this problem are warranted.

One of the unique features of the Juan de Fuca subduction zone is the very young age of the subducting plate. Since the subduction zones used to determine (5) have a subducting plate older than $10 \mathrm{Myr}$, there is some question as to whether (5) applies to the very young Juan de Fuca plate. A recent study by Singh et al (1985), however, demonstrates that the 1932 Jalisco, Mexico, earthquake $\left(M_{\mathrm{s}}=8.2\right)$ occurred on the boundary between the very young $(9 \mathrm{Myr})$ Rivera plate and the North American plate. This boundary is geometrically similar to that between the Juan de Fuca plate and the North American plate.

\section{Aseismic and Seismic Slip}

At the Mariana-type subduction zones, seismicity is so low that the slip associated with earthquakes cannot accommodate the total plate motion; this suggests that a substantial amount of slip is occurring aseismically. Kanamori (1977b) estimated the amount of seismic slip at various subduction zones and concluded that the ratio $\eta$ of seismic slip to the total plate motion is approximately $1,0.25$, and 0 for southern Chile, the Kurile Islands, and the Marianas, respectively. However, these estimates are subject to large uncertainties because of $(a)$ errors in the estimates of seismic slip and $(b)$ incomplete data on the repeat times. Subsequently, Seno \& Eguchi (1983), Sykes \& Quittmeyer (1981), and Peterson \& Seno (1984) have made independent analyses of the data. The results of these four studies are in general agreement, though they differ in details, particularly for subduction zones for which repeat-time data are incomplete. On the basis of these studies, Kanamori \& Astiz (1985) attempted another interpretation of the data. Figure 17 shows the values of $\eta$ as a function of the age of the subducting plate. These values probably depend on various factors such as the convergence rate, the upper plate velocity, the roughness of the oceanic and upper plate, and the structure of the sediment. Figure 17 shows only the effect of $T$ on $\eta$.

Subduction zones with a relatively young subducting plate (ranging from 20 to $60 \mathrm{Myr}$ old) have $\eta$ values very close to 1, and thus interplate slip for these subduction zones is predominantly seismic. For subduction zones with a very old plate, such as the Marianas and northern Japan, $\eta$ is very small, and therefore the plates are almost decoupled. It is interesting to note that the two largest lithospheric normal-fault earthquakes, the 1933 Sanriku and 1977 Sumbawa earthquakes, occurred in lithospheres that are 


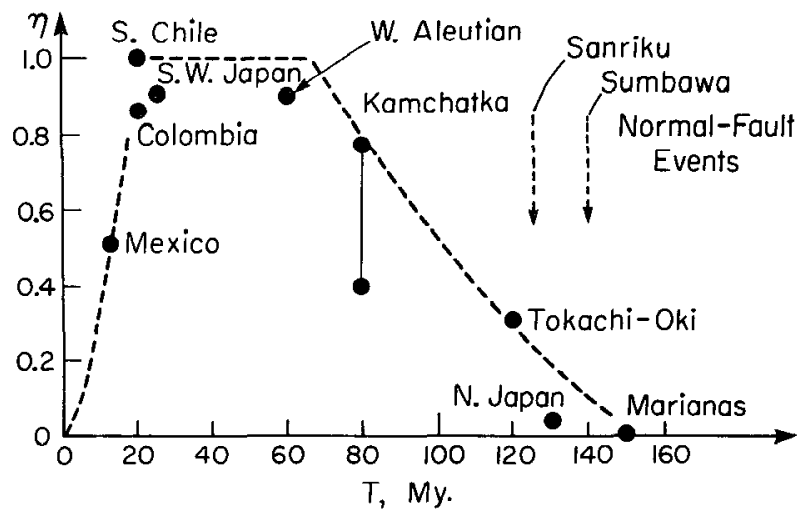

Figure 17 The ratio of seismic slip to total plate motion as a function of the age of the subducting plate (after Kanamori \& Astiz 1985). The two largest lithospheric normal-fault earthquakes (1933 Sanriku and 1977 Sumbawa earthquakes) occurred in lithospheres that are 120 and 140 Myr old, respectively.

120 to $140 \mathrm{Myr}$ old; this suggests that these events result from increased tensional stress caused by plate decoupling.

As $T \rightarrow 0$, the interplate deformation is most likely to be aseismic as a result of high temperatures, and one would expect $\eta$ to approach 0 as $T \rightarrow 0$. Because of the large uncertainty in the data, however, this result should be considered only tentative.

\section{Radiation of High-Frequency Seismic Waves}

The asperity model discussed above was based upon seismic data whose time scale is longer than $10 \mathrm{~s}$. Since the strength of plate coupling and fault heterogeneity (asperities) are most likely to affect the radiation of highfrequency (e.g. $>1 \mathrm{~Hz}$ ) seismic waves, one would expect regional variations in the radiation efficiency of high-frequency waves from earthquakes. A better understanding of high-frequency characteristics of earthquakes is important for predicting earthquake strong ground motions.

In view of the recent increase in the number of large man-made structures, such as high-rise buildings and offshore drilling platforms, estimation of strong ground motions from large earthquakes in subduction zones is becoming increasingly important. However, observed highfrequency waveforms from large earthquakes are very complex, so that a detailed analysis such as the one illustrated by Figure 8 is not feasible. An alternative approach is to determine the frequency spectrum of far-field time functions. Houston \& Kanamori (1986) used digital seismograms, which recently became available, to determine the spectra of a few large 


\section{$318 \quad$ KANAMORI}
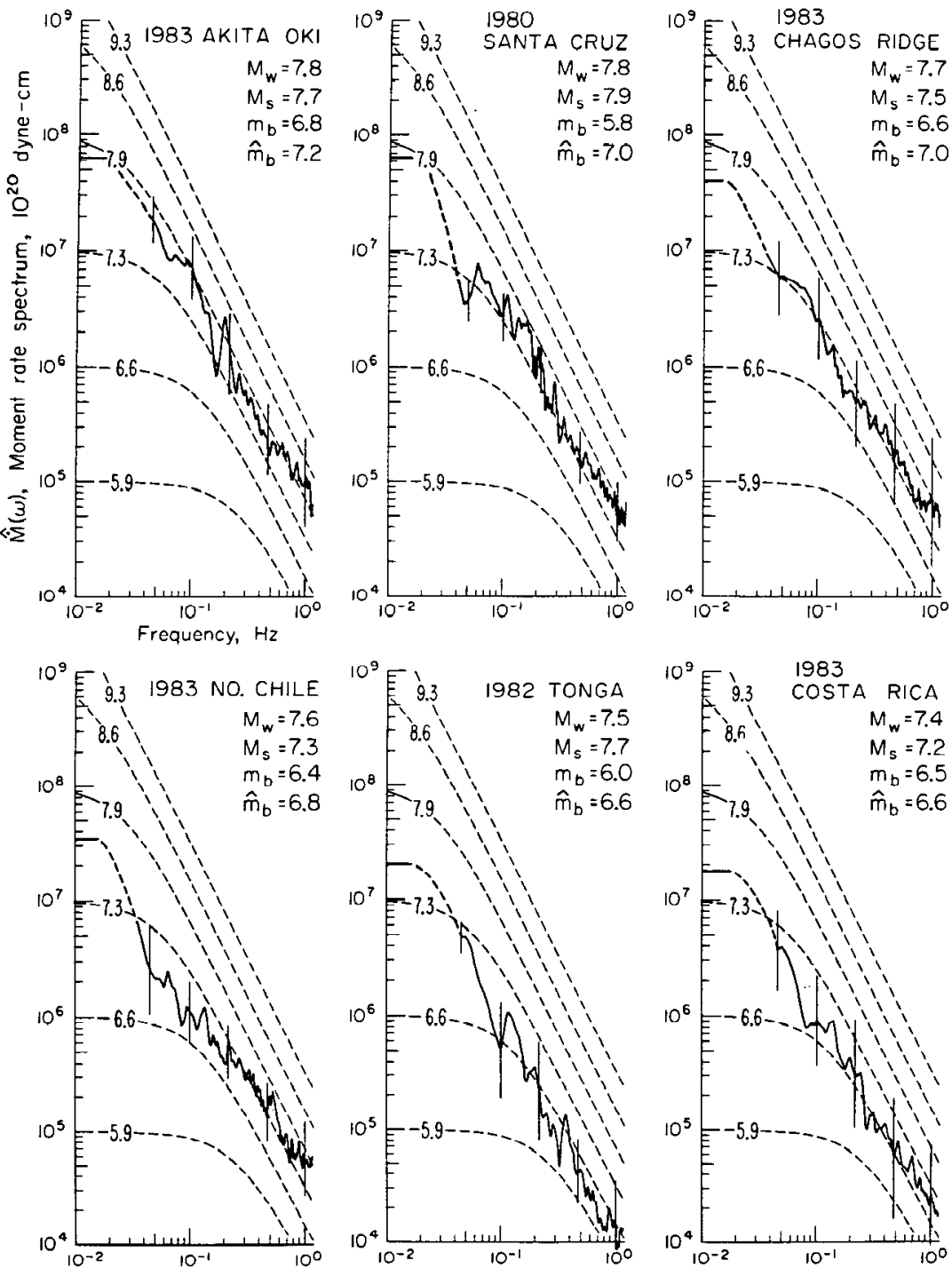

Figure 18 Comparison of source spectra (i.e. spectrum of the source time function, such as the one shown by Figure $8 h$ ) of six large earthquakes. The dashed curves, which are computed for a theoretical source model, are shown for reference. Note that the spectral amplitude of the 1982 Tonga earthquake at $1 \mathrm{~s}\left(10^{\circ} \mathrm{Hz}\right)$ is significantly lower than that for other events. 
subduction-zone earthquakes with comparable magnitudes. The results are shown in Figure 18.

Among the events shown in Figure 18, the event in the Tonga Islands occurred in a Mariana-type subduction zone. Comparing the long-period and short-period spectral amplitudes, we see that the Tonga earthquake has proportionally less high-frequency energy than the other events, possibly because of the weak mechanical coupling at the Tonga subduction zone. Since the presently available data are very limited in quantity, more definitive conclusions must await further studies.

\section{CONCLUSIONS}

The distribution of great earthquakes and fault-zone mechanical heterogeneities inferred from seismic waveforms and expansion patterns of aftershock areas suggest that the nature and strength of interplate coupling at subduction zones vary significantly from place to place. This regional variation can be characterized best by the use of an asperity model, which assumes that a fault zone consists of two parts : mechanically strong spots herein called the asperities, and weaker zones surrounding the asperities. Strongly coupled subduction zones have a fault zone that consists of large and uniform asperities. As the asperity size decreases with increasing area of weak zones, the fault zone becomes more heterogeneous and the strength of plate coupling decreases.

Tectonic features associated with strongly coupled subduction zones such as the Chilean and Alaskan subduction zones include shallow oceanic trenches, shallow dipping Benioff zones, generally andesitic volcanism, and the absence of active back-arc basins. Weakly coupled subduction zones such as the Marianas have tectonic features more or less opposite in nature. This difference is intuitively consistent with the difference in the magnitude of horizontal compressive stress in the trench-arc system associated with the difference in the degree of plate coupling. However, the details of the physical mechanism remain to be investigated.

The magnitude $M_{\mathrm{w}}^{\prime}$ of the largest "characteristic" earthquake of a subduction zone correlates well with the age $T$ of the subducting plate and the convergence rate $V$ in the form $M_{\mathrm{w}}^{\prime}=a T+b V+c(a=-0.00953$, $b=0.143, c=8.01, T$ in $\mathrm{Myr}, V$ in $\mathrm{cm} \mathrm{yr}^{-1}$ ). This relation, though purely empirical, is useful in predicting $M_{\mathrm{w}}^{\prime}$ for subduction zones that have not experienced large earthquakes in historical time.

\section{ACKNOWLEDGMENTS}

I thank Luciana Astiz and Holly Eissler for reviewing the manuscript. Larry Ruff provided me with some figures before publication. This work 
was partially supported by the National Science Foundation under grant EAR-8116023 and the US Geological Survey under contract 14-08-0001G-979. This article is contribution No. 4252 of the Division of Geological and Planetary Sciences.

\section{Literature Cited}

Abe, K. 1981. Magnitude of large shallow earthquakes from 1904 to 1980 . Phys. Earth Planet. Inter. 27:72-92

Aki, K. 1966a. Generation and propagation of $G$ waves from the Niigata earthquake of June 16, 1964. Part 1. A statistical analysis. Bull. Earthquake Res. Inst. Univ. Tokyo 44: 23-72

Aki, K. 1966b. Generation and propagation of $G$ waves from the Niigata earthquake of June 16, 1964. Part 2. Estimation of earthquake moment, from the $G$ wave spectrum, Bull. Earthquake Res. Inst. Univ. Tokyo 44:73-88

Aki, K. 1967. Scaling law of seismic spectrum. J. Geophys. Res. 72:1217-31

Bath, M. 1981. Earthquake magnituderecent research and current trends. Earth Sci. Rev. 17:315-98

Beck, S. L., Ruff, L. J. 1984. The rupture process of the great 1979 Colombia earthquake : evidence for the asperity model. $J$. Geophys. Res. 89:9281-91

Burridge, R., Knopoff, L. 1964. Body force equivalents for seismic dislocations. Bull. Seismol. Soc. Am. 54:1901-14

Byerlee, J. D. 1970. Static and kinetic friction of granite under high stress. Int. J. Rock Mech. Min. Sci. 7:577-82

Caldwell, J. G., Haxby, W. F., Karig, D. E., Turcotte, D. L. 1976. On the applicability of a universal elastic trench profile. Earth Planet. Sci. Lett. $31: 239-46$

Chapple, W. M., Forsyth, D. W. 1979. Earthquakes and bending of plates at trenches. J. Geophys. Res. 84:6729-49

Chung, D. H., Bernreuter, D. L. 1981. Regional relationship among earthquake magnitude scales. Rev. Geophys. Space Phys. 19:649-63

Coulon, C., Thorpe, R. S. 1981. Role of continental crust in petrogenesis of orogenic volcanic associations. Tectonophysics 77 : 79-93

Das, S., Aki, K. 1977. Fault planes with barriers: a versatile earthquake model. $J$. Geophys. Res. 82:5658-70

Geller, R. J. 1976. Scaling relations for earthquake source parameters and magnitudes. Bull. Seismol. Soc. Am. 66:1501-23

Geller, R. J., Kanamori, H. 1977. Magnitude of great shallow earthquakes from 1904 to
1952. Bull. Seismol. Soc. Am. 67:587-98

Gill, J. 1981. Orogenic Andesites and Plate Tectonics. New York: Springer-Verlag. $390 \mathrm{pp}$.

Gutenberg, B. 1945. Amplitudes of surface waves and magnitudes of shallow earthquakes. Bull. Seismol. Soc. Am. 35:3-12

Gutenberg, B., Richter, C. F. 1956. Magnitude and energy of earthquakes. $A n n$. Geofis. 9:1-15

Hager, B. H., O'Connell, R. J. 1981. A simple global model of plate motions and mantle convection. J. Geophys. Res. 86:4843-67

Hager, B. H., O'Connell, R. J., Raefsky, A. 1983. Subduction, back-arc spreading and global mantle flow. Tectonophysics 99 : 165-89

Hanks, T. C., Kanamori, H. 1979. A moment magnitude scale. J. Geophys. Res. 84: 2348-50

Hartzell, S. H., Heaton, T. H. 1985. Teleseismic time functions for large, shallow subduction zone earthquakes. Bull. Seismol. Soc. Am. 75:965-1004

Heaton, T., Kanamori, H. 1984. Seismic potential associated with subduction in the northwestern United States. Bull. Seismol. Soc. Am. 74:933-41

Hilde, T. W. C. 1983. Sediment subduction versus accretion around the Pacific. Tectonophysics $99: 381-97$

Hilde, T. W. C., Sharman, G. F. 1978. Fault structure of the descending plate and its influence on the subduction process. Eos, Trans. Am. Geophys. Union 59: 1182 (Abstr.)

Houston, H., Kanamori, H. 1986. Source spectra of great earthquakes : teleseismic constraints on rupture process and strong motion. Bull. Seismol. Soc. Am. In press

Isacks, B., Oliver, J., Sykes, L. 1968. Seismology and the new global tectonics. $J$. Geophys. Res. 73: 5855-99

Kanamori, H. 1971. Great earthquakes at island arcs and the lithosphere. Tectonophysics 12:187-98

Kanamori, H. 1977a. The energy release in great earthquakes. J. Geophys. Res. 82: 2981-87

Kanamori, H. 1977b. Seismic and aseismic slip along subduction zones and their tectonic implications. In Island Arcs, 
Deep Sea Trenches and Back-Arc Basins, Maurice Ewing Ser., ed. M. Talwani, W. C. Pitman III, 1: 163-74. Washington, DC: Am. Geophys. Union

Kanamori, H. $1977 \mathrm{c}$. Quantification of earthquakes. Nature 271:411-14

Kanamori, H, 1981. The nature of seismicity patterns before large earthquakes. In Earthquake Prediction-An International Review, Maurice Ewing Ser., ed. D. W. Simpson, P. G. Richards, 4:1-19. Washington, DC: Am. Geophys. Union

Kanamori, H. 1983. Magnitude scale and quantification of earthquakes. Tectonophysics 93:185-99

Kanamori, H., Anderson, D. L. 1975. Theoretical basis of some empirical relations in seismology. Bull. Seismol. Soc. Am. 65: 1073-95

Kanamori, H., Astiz, L. 1985. The 1983 Akita-Oki earthquake $\left(M_{\mathrm{w}}=7.8\right)$ and its implications for systematics of subduction earthquakes. Earthquake Predict. Res. 3: 305-17

Kelleher, J., McCann, W. 1976. Buoyant zones, great earthquakes, and unstable boundaries of subduction. J. Geophys. Res. $81: 4885-96$

Kelleher, J., McCann, W. 1977. Bathymetric highs and the development of convergent plate boundaries. In Island Arcs, Deep Sea Trenches and Back-Arc Basins, Maurice Ewing Ser., ed. M. Talwani, W. C. Pitman III, 1:115-22. Washington, DC: Am. Geophys. Union

Kelleher, J., Savino, J. 1975. Distribution of seismicity before large strike-slip and thrust-type earthquakes. J. Geophys. Res. $80: 260-71$

Kelleher, J., Savino, J., Rowlett, H., McCann, W. 1974. Why and where great thrust earthquakes occur along island arcs. $J$. Geophys. Res. 79:4889-99

Kikuchi, M., Fukao, Y. 1985. Iterative deconvolution of complex body waves from great earthquakes - the Tokachi-Oki earthquake of 1968. Phys. Earth Planet. Inter. 37:235-48

Lay, T., Kanamori, H. 1980. Earthquake doublets in the Solomon Islands. Phys. Earth Planet. Inter. $21: 283-304$

Lay, T., Kanamori, H. 1981. An asperity model of great earthquake sequences. In Earthquake Prediction-An International Review, Maurice Ewing Ser., ed. D. W. Simpson, P. G. Richards, 4 : 579-92. Washington DC: Am. Geophys. Union

Lay, T., Kanamori, H., Ruff, L. 1982. The asperity model and the nature of large subduction zone earthquakes. Earthquake Predict. Res. 1:3-71

Madariaga, R. 1979. On the relation between seismic moment and stress drop in the presence of stress and strength heterogeneity. J. Geophys. Res. $84: 2243-50$

Malgrange, M., Deschamps, A., Madariaga, R. 1981. Thrust and extentional faulting under the Chilean coast: 1965, 1971 Aconcagua earthquakes. Geophys. $J, R$. Astron. Soc. 66:313-31

Maruyama, T. 1963. On the force equivalents of dynamical elastic dislocations with reference to the earthquake mechanism. Bull. Earthquake Res. Inst. Univ. Tokyo $41: 467-86$

Miyashiro, A. 1974. Volcanic rock series in island arcs and active continental margins. Am. J. Sci. 274:321-55

Mogi, K. 1968. Sequential occurrences of recent great earthquakes. J. Phys. Earth $16: 30-36$

Mogi, K. 1969a. Relationship between the occurrence of great earthquakes and tectonic structures. Bull. Earthquake Res. Inst. Univ. Tokyo 47:429-41

Mogi, K. 1969b. Some features of recent seismic activity in and near Japan, (2) Activity before and after great earthquakes. Bull. Earthquake Res. Inst. Univ. Tokyo 47:395-417

Molnar, P., Atwater, T. 1978. Inter-arc spreading and cordilleran tectonics as alternates related to the age of subducted oceanic lithosphere. Earth Planet. Sci. Lett. $41: 330-40$

Newcomb, K. R., McCann, W. R. 1984. Seismic history and seismotectonics of the Sunda arc. Preprint (Lamont-Doherty Geol. Obs., Palisades, N.Y.)

Peterson, E. T., Seno, T. 1984. Factors affecting seismic moment release rates in subduction zones. J. Geophys. Res. 89:1023348

Purcaru, G., Berckhemer, H. 1978. A magnitude scale for very large earthquakes. Tectonophysics $49: 189-98$

Richter, C. F. 1935. An instrumental earthquake magnitude scale. Bull. Seismol. Soc. Am. 25:1-32

Rudnicki, J. W., Kanamori, H. 1981. Effects of fault interaction on moment, stress drop and strain energy release. J. Geophys. Res. 86: 1785-93

Ruff, L. J. 1985. Do trench sediments affect subduction zone seismicity? In Earthquake Source Mechanics, Maurice Ewing Ser., ed. S. Das, Vol. 5. Washington, DC: Am. Geophys. Union. In press

Ruff, L., Kanamori, H. 1980. Seismicity and the subduction process. Phys. Earth Planet. Inter. $23: 240-52$

Ruff, L., Kanamori, H. 1983a. The rupture process and asperity distribution of three great earthquakes from long-period dif- 
fracted $P$-waves. Phys. Earth Planet, Inter. $31: 202-30$

Ruff, L., Kanamori, H. 1983b. Seismic coupling and uncoupling at subduction zones. Tectonophysics $99: 99-117$

Scholl, D. W., Marlow, M. S., Cooper, A. K. 1977. Sediment subduction and offscraping at Pacific margins. In Island Arcs, Deep Sea Trenches and Back-arc Basins, Maurice Ewing Ser., ed. M. Talwani, W. C. Pitman III, 1:199-210. Washington DC: Am. Geophys. Union

Scholz, C. H., Engelder, J. T. 1976. The role of asperity indentation and ploughing in rock friction-1. Asperity creep and stick-slip. Int. J. Rock. Mech. Min. Sci. Geomech. 13:149-54 (Abstr.)

Schwartz, S., Ruff, L. 1985. The 1968 Tokachi-Oki and the 1969 Kurile Islands earthquakes: variability in the rupture process. J. Geophys. Res. 90: 8613-26

Seno, T., Eguchi, T. 1983. Seismotectonics of the western Pacific region. In Geodynamics of the Western Pacific-Indonesian Region, Geodyn. Ser., ed. T. W. C. Hilde, S. Uyeda, 11:5-40. Washington, DC: Am. Geophys. Union/Geol. Soc. Am.

Singh, S. K., Ponce, L., Nishenko, S. P. 1985. The great Jalisco, Mexico, earthquake of 1932 and the Rivera subduction zone. Bull. Seismol. Soc. Am. 75:1301-13

Stauder, W. 1968. Tensional character of earthquake foci beneath the Aleutian trench with relation to sea floor spreading. J. Geophys. Res. 73:7693-7701

Steketee, J. A. 1958. On Voltera's dislocations in a semi-infinite elastic medium. Can. J. Phys. 36: 192-205

Sykes, L. R., Quittmeyer, R. C. 1981. Repeat times of great earthquakes along simple plate boundaries. In Earthquake Prediction-An International Review, Maurice Ewing Ser., ed. D. W. Simpson, P. G. Richards, 4:217-47. Washington, DC: Am. Geophys. Union
Tajima, F., Kanamori, H. 1985a. Global survey of aftershock area expansion patterns. Phys. Earth Planet. Inter. 40:77-134

Tajima, F, Kanamori, H, 1985b. Aftershock area expansion and mechanical heterogeneity of fault zone within subduction zones. Geophys. Res. Lett. 12:345-48

Taylor, F. W., Isacks, B. L., Jouannic, C., Bloom, A. L., Dubois, J. 1980. Coseismic and Quaternary vertical tectonic movements, Santo and Malekula Islands, New Hebrides island arc. J. Geophys. Res. 85: 5367-81

Uyeda, S. 1982. Subduction zones : an introduction to comparative subductology. Tectonophysics $81: 133-59$

Uyeda, S. 1984. Subduction zones: their diversity, mechanism and human impacts. GeoJournal 8:381-406

Uyeda, S., Kanamori, H. 1979. Back-arc opening and the mode of subduction. $J$. Geophys. Res. 84: 1049-61

Vlaar, N. J., Wortel, M. J. R. 1976. Lithospheric aging, instability, and subduction. Tectonophysics 32:331-51

Ward, S. N. 1983. Body wave inversion: moment tensors and depths of oceanic intraplate bending earthquakes. J. Geophys. Res. 88:9315-30

Watts, A. B., Talwani, M. 1975. Gravity anomalies seaward of deep-sea trenches and their tectonic implications. Geophys. J. R. Astron. Soc. 36:57-90

Wortel, M. J. R., Vlaar, N. J. 1978. Agedependent subduction of oceanic lithosphere beneath western South America. Phys. Earth Planet. Inter. 17:201-8

Yonekura, N. 1983. Late Quaternary vertical crustal movements in and around the Pacific as deduced from former shoreline data. In Geodynamics of the Western Pacific-Indonesian Region, Geodynamics Ser., ed. T. W. C. Hilde, S. Uyeda, $11: 41-$ 50. Washington, DC: Am. Geophys. Union/Geol. Soc. Am. 
A Annual Review of Earth and Planetary Sciences

R Volume 14, 1986

\section{CONTENTS}

Geophysics on Three Continents, Anton L. Hales 1

TRIGGERED EarthQuaKES, D. W. Simpson 21

El Nĩ̃o, Mark A. Cane $\quad 43$

Molecular Phylogenetics, Jerold M. Lowenstein 71

Conodonts and Biostratigraphic Correlation, Walter $C$.

Sweet and Stig M. Bergström

Occurrence and Formation of Water-Laid Placers, Rudy

Slingerland and Norman D. Smith

EarthQuakes and Rock Deformation in Crustal Fault

ZONES, Richard H. Sibson

Genesis of Mississippi Valley-Type Lead-Zinc Deposits,

Dimitri A. Sverjensky

Carbon Dioxide Increase In the ATMosphere and Oceans and

Possible Effects on Climate, Chen-Tung A. Chen and Ellen

T. Drake

201

Coastal Processes and the Development of Shoreline

Erosion, Paul D. Komar and Robert A. Holman 237

Forecasting Volcanic Eruptions, Robert $W$. Decker

Rupture Process of Suduction-Zone EarthQuakes, Hiroo

Kanamori

GeOchemistry of TekTtTes aNd ImPaCt Glasses, Christian

Koeberl

Climatic Rhythms Recorded in Strata, Alfred G. Fischer

Temperature Distribution In the Crust and Mantle,

Raymond Jeanloz and S. Morris

Petrogenesis of ANDEsites, Timothy L. Grove and Rosamond $J$.

Kinzler

Geologic Significance of Paleozoic and Mesozoic

Radiolarian Chert, David L. Jones and Benita Murchey

Chemical Geodynamics, Alan Zindler and Stan Hart

INDEXES

Subject Index

Cumulative Index of Contributing Authors, Volumes 1-14

Cumulative Index of Chapter Titles, Volumes 1-14 